\title{
Curbs on Panic and Pesticides
}

CERTAIN uses of DDT and other organochlorine pestieides in Britain are to be banned as soon as possible, following acceptance by the Minister of Agriculture of the recommendations made by the Advisory Committee on. Pesticides and Other Toxic Chemicals. The committee found no evidence that the residues of the pesticides in the environment are harmful to man, but on the principle that their presence is undesirable, it recommended that alternative pesticides should, where possible, be used.

The pesticides whose use has been restricted include DDT, aldrin, endrin, dieldrin, TDE and heptachlor. About 400 tons of these chemicals are used each year in Britain and the recommendations are expected to halve this amount. The restrictions affect uses of the organochlorines in agriculture, horticulture, food storage, home gardens and kitchens.

The committee has Dr Andrew Wilson, professor of pharmacology at Liverpool, as chairman, and appointed as chairman of its scientific subcommittee Professor M. Cohen of the Plant Pathology Laboratory. In reviewing the uses of DDT, the committee was belatedly discharging the advice of its predecessor which recommended in 1964 that the use of DDT "should be reviewed at the end of three years". The principal evidence, a survey of the use of organochlorines in agriculture and horticulture, was completed by the Plant Pathology Laboratory in November 1968, but it has taken a year for the report to see the light of day.

The report is a thorough document which reviews the effects of the organochlorines on wildlife and man and their distribution in food and the environment as well as the commercial and domestic uses of the substances (Further Review of Certain Persistent Organochlorine Pesticides Used in Great Britain. HMSO, $12 s 6 d$ ).

The committee "found no evidence of recent widespread deaths among birds attributable to single or short term intakes of the chemicals under review" although certain local casualties tend to occur. The evidence available indicates that dieldrin was responsible for the marked declines in the population of peregrine falcons and sparrow hawks that started in 1955 and began to recover in 1966. (The use of dieldrin was heavily restricted in 1964.)

It is true that the eggshells of peregrine falcons and sparrowhawks became thinner in the late 1940s and have stayed thinner ever since, which parallels quite closely the growth in the use of DDT, but this evidence "is not precise enough to establish a causal relationship with certainty".

The committee finds that DDT incorporated into the topsoil may take 3 to 6 years to decline by 50 per cent, but that the rate of loss diminishes with time. Although the amounts of DDT commonly found in soil have marked effects on soil invertebrates, they "do not influence significantly the total number of soil microorganisms or the beneficial processes for which they are responsible". Above ground, DDT "reduces both numbers and the range of species of beneficial arthropods" but the status quo ante is generally restored a few years after cessation of use.
Little is known about the effects of DDT on fish in Britain and there is "no evidence to suggest that acute DDT poisoning is occurring very widely among birds in Britain" although many wild birds contain residues of DDT or its metabolite DDE. Although there is experimental evidence that DD' can delay the attainment of sexual maturity in some species of birds, the production, fertility and viability of eggs "are not seriously affected by DDT except at levels that affect the general physiological state of the birds".

Turning to man, the committee estimates from samples of food its inspectors have bought and analysed that the average daily intake of organochlorines, in micrograms per kilogram of body weight, is as follows (figures in parentheses are the acceptable daily intakes proposed by the FAO/WHO expert committee on pesticide residues): DDT $0 \cdot 6(10 \cdot 6)$, dieldrin $0 \cdot 1(0 \cdot 1)$, BHC $0 \cdot 2(12 \cdot 5)$. The most recent survey suggests that in Britain the quantity of organochlorine residues in human fat is tending to fall rather than rise.

What are the effects of DDT on man? The committee notes that "experiments on animals can provide only presumptive evidence that similar effects will occur in man", but it notes with concern experiments reported from Hungary in which a high incidence of leukaemia occurred in the third generation of mice whose parents were fed a diet with a low dose of DDT. The World Health Organization has arranged a repetition of this experiment, the results of which will not be available for two years; meanwhile, the committee remains in doubt as to how to interpret these experiments, "the implications of which could be so important that we believe these data must be discussed, and agreement on their interpretation reached on an international basis". Nevertheless, although dieldrin and DDT occur in human body fat, there is "no evidence that this results in any adverse affects on man".

In summary, the committee considers it "undesirable that the human environment should contain substances capable of producing toxic effects and whose continued presence conveys no benefit to human survival and well-being. If, however, priority is given to the removal of those substances, the presence of which is known to be harmful to man, then on such a basis no high priority can presently be assigned to the removal of DDT or dieldrin. ... We believe that the problem of persistent organochlorine pesticides in the environment is only part of the larger problem of pollution of the environment by man; and, although important, it should be looked at against the background of pollution arising from industrial and domestic effluents".

Finally, it should be noted that the Wilson Committee, unlike the Committee on Drug Safety in its recent pronouncement on the contraceptive pill, emphasizes that its conclusions apply to Britain alone and need not necessarily relate to other countries. Nor does the committee neglect to recommend that no use of the pesticides should be denied for research. 